\title{
Educating Students in Technology Enhanced Learning Design by Interweaving Instruction and Assessment
}

\author{
Agoritsa GOGOULOU, Maria GRIGORIADOU
}

Department of Informatics \& Telecommunications, National and Kapodistrian University of Athens Panepistimioupolis, Ilisia, Athens 157 84, Greece

e-mail:rgog@di.uoa.gr,gregor@di.uoa.gr

Received: August 2020

\begin{abstract}
Developing an engaging and positive learning environment for learners, especially in a particular course, is one of the most creative aspects of teaching. Learning design supports the design of interventions, which are pedagogically informed, promote student-centered learning activities and make effective use of appropriate resources and technologies. In the context of this work, a framework is proposed for teaching learning design issues in tertiary education which interweaves teacher-centered activities with student-centered activities. The students are engaged in lab activities and in a learning design peer assessment project. Sustainable feedback practices are considered an integral part of the whole process. Findings drawn from an empirical study carried out during two consecutive academic years reveal that the interweaving of instruction and assessment may contribute to the understanding of the main learning design issues and to the cultivation of skills both in the development of educational applications as well as in the design of technology enhanced learning activities.
\end{abstract}

Keywords: instruction, peer assessment, feedback, learning design, lab activities.

\section{Introduction}

Teaching is a core function of higher education (Barnard et al., 2011). Teachers' approaches to teaching are influenced by their conceptions of teaching. Teachers who conceive teaching as transmitting knowledge are more likely to adopt a teacher centered approach to teaching, while those who conceive teaching as interactive and supportive process, tend to use student centered approaches (Postareff et al., 2007). Instruction in higher education is dominated by one-size-fits-all pedagogical method (Ernst and Ernst, 2005). The teacher-centered model of lecture-style teaching sets students up for failure (Dosch and Zidon, 2014). Some instructors assume their job is done after they tell students the content of the course and consider that they transmit the knowledge to the students. However, telling or presenting is not effective pedagogy. 
Effective teaching methods in higher education focus on the students' activity rather than just the acquisition of facts, on opportunities for meaningful personal interaction between the students and teachers, on more authentic methods of assessment including elements of peer and self-assessment (Shirani Bidabadi et al., 2016). A key way to bring teaching and learning together and engage students as partners is through the assessment process. Assessment and feedback processes have a significant impact on 'what, how and how much students study' (Gibbs and Simpson, 2004) and is, therefore, an essential element in the learning and teaching process. Sadler (1989, p. 123) wrote "formative assessment refers to assessment that is specifically intended to generate feedback on performance to improve and accelerate learning". The notion of feedback is expanded to include not only the usual tutor feedback on student work but also dialogic feedback, which is part of interactive teaching and learning as well as peer feedback in the context of various peer learning / assessment activities. The peer feedback enables students to identify the strengths and weaknesses of their own work, it is readily available in much larger quantity and more immediately than teacher feedback (Sambell, 2013; Topping, 2017). In order to encourage deep rather than surface approaches to learning and inspire students to devote time and effort, it is necessary to support well-designed, carefully integrated and sequenced assessment practices (Gibbs, 2006). Along with assessment, sustainable feedback practices are required which prompt learner action, view peers as active sources of feedback, change teachers' role to facilitators of learning, and help students to understand standards and criteria which guide their progress and strengthen learning and instruction (Sambell, 2016).

Within universities and organizations, there is growing recognition for the importance of technology-enhanced learning and learning design. The use of ICT tools like wikis and forums, educational software and simulations and open educational resources, results into increase of students' engagement and support of deep learning (Santos et al., 2019). A number of courses (mostly in the form of MOOC) and seminars are offered world-wide focusing on learning theories and interactive technologies, on instructional design models, on defining and assessing learning outcomes, etc. During the course, the students are faced with various instructional and technological obstacles that may affect their performance. From an instructional-pedagogical perspective, the most indicative ones are the lack of the main instructor's support and the lack of technological affordances for users' interaction (Kazanidis et al., 2018).

Although Gilbert (2016) states that there is still a place for the lecture in 21 st century higher education and one should consider their role and value in learning in higher education, active learning is seen as a more powerful approach. Santos and her colleagues (2019) in their attempt to conduct an integrative literature review on innovative pedagogical practices in higher education highlight the use of peer evaluation, formative evaluation, active and collaborative learning, flipped classrooms, and mixed approaches with ICTs association, as pedagogical practices that promote students' involvement and their conceptual change. Despite a growing body of literature and considerable investment by universities, feedback continues to be poorly understood and enacted by both educators and students (Henderson et al., 2019). 
In this direction, our work seeks to extend and enhance the existing pool of effective practices in the field of designing technology enhanced learning settings. We propose an integrated pedagogical framework that combines different pedagogical practices in order to provide a learning setting that facilitates active engagement and promotes the acquisition of meaningful skills in designing technology enhanced learning situations. The framework combines instruction and formative assessment and exploits peer assessment; the students are actively involved in various activities and a learning design peer-assessment project. The provision of suitable feedback is an essential part of the whole process. The specific interest of our work lies in the insights it provides for both researchers and practitioners in the field of pedagogical practices in higher education and also in training focusing on learning design issues.

\section{Theoretical Background}

\subsection{Learning Design Issues}

According to the idea of learning design the role of instruction is "not to transmit knowledge to a passive recipient, but to structure the learner's engagement with knowledge, practicing the high-level cognitive skills that enable them to make that knowledge their own" (Laurillard, 2008, p.527). Conole (2013) defines learning design as "a methodology for enabling teachers/designers to make more informed decisions in how they go about designing learning activities and interventions, which is pedagogically informed and makes effective use of appropriate resources and technologies. This includes the design of resources and individual learning activities right up to curriculum-level design. A key principle is to help make the design process more explicit and shareable." In a more general sense, learning design is defined as the description of the teachinglearning process that takes place in a unit of learning (e.g. course, lesson, seminar, workshop). The field of learning design has the ultimate goal of improving teaching quality by supporting practitioners along the process of designing innovative and more effective learning situations, that is, producing "learning designs" (Hernández-Leo et al., 2018). The central argument of learning design is that adopting a more principled, design-based approach to teaching and learning processes might offer a solution to enabling teachers to make more informed choices about their creation of learning interventions and better use of good pedagogy and new technologies (Conole, 2010). A "learning design" is an artifact that explicitly documents a set of learning tasks with the set of resources and tools that support the realization of the tasks (Hernández-Leo et al., 2018), that is a technology enhanced learning (TEL) environment.

In learning design, the emphasis is on the pedagogical intent, following high-level design principles positioned in the framework of socio-cultural educational research (Celik and Magoulas, 2016). The learning design emphasizes more on the learner's context and the constructivist approach in the learning activities and aims at the formation of learning environments that provide learners with opportunities to learn. In this sense, in order to establish effective learning environments, appropriate teaching material and 
learning activities have to be designed and learners to be engaged actively and act reflectively about the issues to be learned. Moreover, continuous feedback may help and guide learners appropriately in refinement of knowledge.

In accord with these prevailing principles, many researchers assert that there is an intimate association between instruction, learning, and assessment (Pellegrino et al., 2001). Berry (2008) points out that assessment for learning should be used to promote, induce, and reinforce learning while Hawe and Dixon (2017) report that assessment for learning fosters the interdependence of teaching, learning and assessment, and challenges the view of assessment as a peripheral component of pedagogy. The terms assessment for learning and formative assessment may be used interchangeably if they reflect practices by students, teachers and peers that seek to enhance ongoing learning (Hawe and Dixon, 2017). Strategies for implementing assessment for learning include the use of questions and activities to probe for deep understanding, provision of feedback focusing on how to improve, rather than on how well the student had done, and peer-assessment and self-assessment giving students rubrics and time to assess their own and each other's work (Black et al., 2003; Panadero and Brown, 2017).

\subsection{Forms of Assessment and Tools}

There has been much clearer recognition of the importance of formative assessment which concentrates on how students can learn more effectively through high quality feedback (Black et al., 2003; Gipps, 2011). Contemporary assessment methods attempt to change the place and the function of the assessor and involve students actively in the assessment process. Peer-assessment is one aspect of formative assessment which aims to lead towards a student-centered learning environment, where assessment is represented as a tool for learning, and achieves goals that are difficult to attain with traditional assessment methods (Sluijsmans et al., 1999). Along with these views, Carless (2015) specifies three core elements as essential for learning-oriented assessment (a) assessment tasks that stimulate sound learning and learning practices among students, (b) active involvement of students in their learning through engagement in self-assessment and/or peer-assessment activities with criteria, and (c) feedback which is timely and supportive for current and future learning.

Researchers have argued that peer assessment has significant benefits for students learning in a variety of contexts (Topping, 2017); it helps them to become more involved and engaged in learning and enhance their understanding of success criteria. Peer-assessment enables students to develop skills in giving and receiving feedback, critical thinking, evaluative abilities and regulation, see how others tackle/solve problems, get inspiration from their peers' work, learn to criticize constructively, accept peer criticism, reflect on the amount of effort they put into their work, develop a wide range of transferable, cognitive and behavioural skills (Sluijsmans et al., 1999; Sung et al., 2005, Panadero and Brown, 2017; Adachi et al., 2018).

Summative definitions of peer assessment have involved students giving one another grades or marks for their work (Strijbos and Sluijsmans, 2010) where the outcome 
counts towards a degree level qualification in higher education (Topping, 2010). Scoring another peer's work might make students feel uncomfortable as it places them in a teacher-like role. Furthermore, such an approach is likely to limit the effectiveness of learning during peer-assessment as a grade/mark alone may fail to diagnose strengths and developmental areas in the assessed work (Davies, 2006). As reported in (Popescu, 2017) peer review also has potential pitfalls, such as validity, reliability and fairness issues, especially in case of peer grading.

Advances in computer and network technology enable the development of educational settings that implement effectively peer-assessment. Dedicated environments have been developed in the context of research projects aiming to fulfill specific objectives and needs but they are not publicly available. In their systematic review of technology-supported peer assessment studies, Zheng and her colleagues (2019) report that most studies adopted general tools, like learning management systems and a few used dedicated peer assessment tools. As Web 2.0 emerging technologies are gaining attention in teaching and learning, the exploitation of web 2.0 tools such as wiki seems to be a promising tool for peer-assessment activities ( $\mathrm{Ng}$ and Lai, 2012; Tsai et al., 2015; Gogoulou and Grigoriadou, 2019). Moreover, in recent years some attempts utilize Google Forms for assessment purposes in higher education. Google Forms is a free tool for anyone with a Google account and a survey technology that is designed to quickly send out questionnaires or surveys and receive data in a timely and organized fashion. They are completely customizable, so users can create the quiz or survey s/he wishes. Google Forms are used to periodically collect information about the course instruction as a form of formative feedback in order to adapt the learning process to a learner-centric environment (Djenno et al., 2015) or to survey students outside of class to learn about them as individuals, to engage them in class by collecting responses in the moment, to collect their self-reflections after a lesson (Nguyen et al., 2018) or to support forms of assessment (Haddad and Youakim, 2014).

\section{The Framework}

The course of "Design and Implementation of Digital Educational Applications" is being offered more than fifteen years in the context of the Master's Degree on Information and Communications Technologies in the Department of Informatics \& Telecommunication of Athens, aiming students to become acquainted with the main principles of learning theories and their realization in educational applications, learning design issues, affordances of learning technologies and ways to incorporate them in order to support technology enhanced learning, main issues in the development and evaluation of educational applications, the notion of learning objects and their educational employment in the context of designing learning activities. The course is mainly lecture-based while the students in order to successfully complete the course have to prove that they have acquired sufficient knowledge and skills in the design of educational applications and their utilization in the design of learning activities. The sharing of material, the implementation of the assignments and the interaction between teacher and students is facilitated by 
a free course management system (eclass). During the winter semester of the academic year 2018-2019, the course was re-organized and updated mainly in terms of pedagogical practices followed. Our approach to teaching was viewed as knowledge facilitation and knowledge application having a strategy towards student-focused learning setting (Santos et al., 2019).

Developing an engaging and positive learning environment for learners, especially in a particular course, is one of the most creative aspects of teaching. The learning environment comprises of (i) the learners' characteristics, (ii) the learning goals, (iii) the activities that will best support learning, and (iv) the assessment strategies that will drive learning (Bates, 2019). Rather than spending a lot of time on theories and models, the focus was shifted to more actionable techniques in the direction of interweaving instruction and assessment in order to provide a learning environment that promotes learning opportunities and fosters achievement of intended learning goals. In this context, a pedagogical framework is proposed which interweaves teacher-centered activities with student-centered activities and forms of assessment (Fig. 1). The framework adopts integrative learning with continuous assessment and seeks to promote active and interactive learning (Jääskelä et al., 2017). More specifically, instruction is combined with various forms of assessment; formative assessment followed by continuous feedback provision and peer assessment using structured assessment forms as good peer assessment requires structure and guidance, such as rubrics (Panadero et al., 2013). The aim is students to follow through with the learning design constructively and supportively.

The lessons take place on a computer lab so that students can have access to digital applications and work on activities. In particular, the students are engaged in nine activities aiming to gradually introduce them in learning design. As learners are more likely to benefit from feedback that is timely, relevant, and appropriate in terms of its content and how it is offered (Armellini and Aiyegbayo, 2010) and also it is more personalised (Henderson, et al., 2019), the teacher, in addition to the lectures and ma-

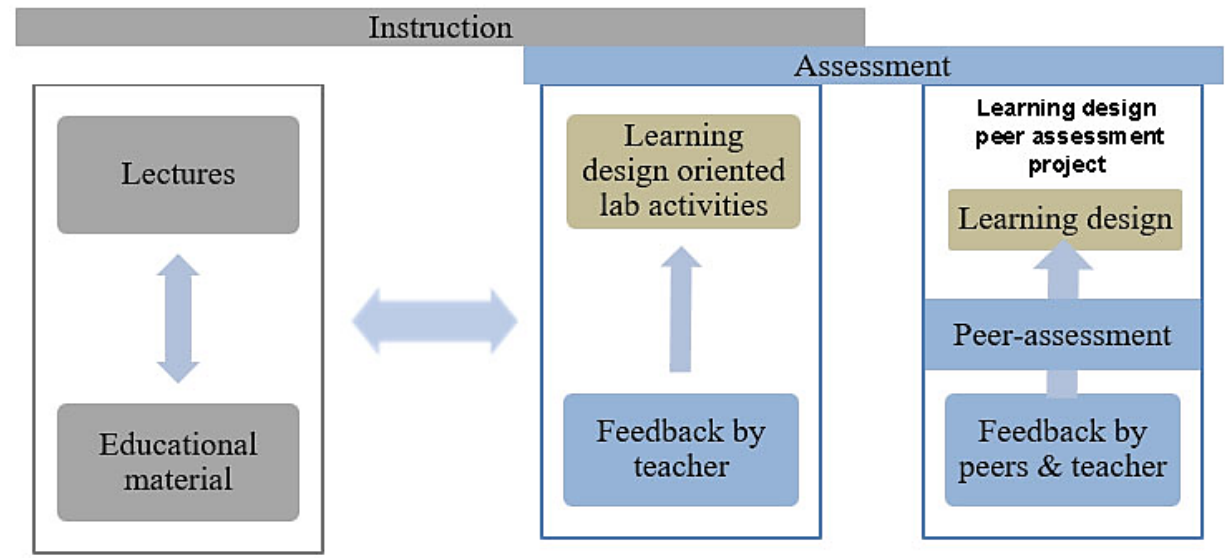

Fig. 1. A framework interweaving instruction and assessment. 
terial, also provides feedback to each student for each activity that s/he works on and submits through the eclass system. The feedback is timely on a weekly basis as it is considered important to be given after the task (Adachi, et al., 2018) and focuses on the specific features of the task and provides suggestions on how to improve (William, 2011). For example, in the context on the activity related to the design of a learning activity using learning objects, the feedback attempts to give students ideas and to make them think on more constructive and interactive approaches to learning. Emphasis is given to characteristics of educational applications and learning activities that espouse constructivism and promote user active involvement and result in non-trivial learning settings. As practice in classroom is formative to the extent that evidence about student achievement is elicited and interpreted, the next steps in instruction attempt to support students in learning design and design of educational applications by discussing specific issues, providing relative material, and designing suitable learning activities. In this sense, the feedback focuses on both the positive and negative aspects of students work and is both verbal and written (Henderson et al., 2019); (a) verbal, while students carry out the activity at the lab, the teacher discusses with them various points that arise and bother students, (b) written via eclass environment after submitting their work that completed as homework, and (c) verbal, in the form of follow-up discussion during the lessons.

\subsection{Curriculum Organized Around Activities}

During weekly lessons, students participate in lectures, face-to-face discussions and a number of activities. Table 1 presents the main topics and the activities carried out.

Table 1

Curriculum organized around lab activities

\begin{tabular}{|c|c|}
\hline Topic & Activities \\
\hline $\begin{array}{l}\text { Concepts related to technology enhanced learn- } \\
\text { ing, to educational applications, to learning }\end{array}$ & $\begin{array}{l}\text { Study and discussion of specific learning theories and prin- } \\
\text { ciples, implied didactic models and educational applications }\end{array}$ \\
\hline $\begin{array}{l}\text { Educational software-educational applica- } \\
\text { tions - Educational Repositories }\end{array}$ & $\begin{array}{l}\text { Exploration of educational repositories and learning objects - } \\
\text { proposals for educational usage }\end{array}$ \\
\hline Behaviorism and educational applications & $\begin{array}{l}\text { Exploration of learning objects and educational software/ap- } \\
\text { plications following principles of behaviorism }\end{array}$ \\
\hline Constructivism and educational applications & $\begin{array}{l}\text { Exploration of learning objects and educational software/ap- } \\
\text { plications following principles of constructivism }\end{array}$ \\
\hline Constructionism & Design of learning activities utilizing related learning objects \\
\hline Social Constructivism \& Connectivism & $\begin{array}{l}\text { Web } 2.0 \text { tools e.g. use of wikis for sharing ideas on learning } \\
\text { objects educational affordances }\end{array}$ \\
\hline Digital Story Telling & Web 2.0 tools for comic, interactive video, simulation \\
\hline Game - based learning & Design and development of educational games \\
\hline $\begin{array}{l}\text { Development and evaluation of educational } \\
\text { software }\end{array}$ & Design of learning objects and learning activities \\
\hline
\end{tabular}


The activities gradually introduce students and familiriase them with concepts of learning, learning theories, educational applications, learning objects and give them the chance to delve into pedagogy and technology issues, exchange ideas related to the educational usage of applications in the context of technology enhanced learning environments, design learning objects (like digital stories, interactive videos, simulations) and propose ways of utilizing them in learning. The context of the activities attempt to cover the learning goals gradually and support the learning design peer assessment project as well as to fulfil the needs of the diverse population of students (Henderson et al., 2019).

\subsection{Learning Design Peer Assessment Project}

In order to integrate the knowledge and skills developed in a creative work and subsequently successfully complete the course, the students are asked to carry out a learning design peer assessment project. The learning design part specifies the design of a technology enhanced learning setting, that is to develop educational applications and design learning activities in order to achieve specific learning outcomes in the context of a specific curriculum either for primary, secondary or higher education or even in the context of adults education in a specific field. Following their role as learning designers, the peer assessment part of the project asks them to act as assessors of learning designs by peer assessing their colleague's work.

In the context of the learning design, the students have to decide on the learning objects to develop and the technology to use (e.g. Web 2.0 tools, free platforms for developing educational games and simulations) and orchestrate the delivery of learning resources (e.g. learning objects) and learning activities in a technology enhanced learning environment. In the context of the study, the learning object is considered as "any digital resource that can be reused to support learning" (Wiley, 2000). In this sense, a learning object may be a digital image, a live or pre-recorded or interactive video, small bits of text, animations, comics, presentations, web-delivered applications, like Java applications or entire web pages that combine text, images and other media. The learning design involves

- Description of learning resources/objects in terms of subject matter, learning goals (in the form of learning outcomes), pedagogical principles followed, educational usage and affordances in the educational process, technological characteristics.

- Structure, sequence, content and scheduling of the learning activities accompanied by analytic descriptions of the learning theories and principles applied, the learning objects utilized and how they serve the underlying learning principles.

The students are urged to form pairs and work; if they don't manage to do so, they work on their own designing for smaller learning units. After submitting their work, 
they have to present their design in front of the whole class and welcome feedback. This feedback can be delivered in a variety of forms including written comments, grading, or verbal feedback (Topping, 1998). In our case, we use all forms. Upon completion, all students may ask for clarification and may comment on the presented learning design. Besides, the student or pair of students that have been designated to act as peer-assessors as well as the teacher have to fill in an assessment form with closed and open-end questions (assessment criteria). The students don't know their assessors in advance and the assessors are informed for the students to assess when they have completed the design part of the project and are ready to present it. As the learning effect of receiving peer feedback depends on the quality of the feedback by the assessor (Gielen and Wever, 2012) and learning is cultivated in reflection processes, the student-assesse has to comment on the feedback s/he received by expressing her/his agreement and referring to any revisions s/he would make to her/his learning design on the basis of the feedback received.

Since eclass environment does not provide the necessary functionality to implement peer assessment activities, the application of Google Forms is proposed. Google Forms is a web-based user-friendly application that facilitates the design and completion of online surveys, questionnaires, and quizzes and may contain a wide range of question types and options and is shared via email. The analysis is facilitated as the responses from Google Forms may be organized into Google Sheets documents as soon as the respondent submits the form.

The assessment form, which is available to the students from the beginning of the project, has the form of a rubric and contains criteria that address the main axes of students learning design, that is:

(a) Learning outcomes.

(b) Learning objects developed.

(c) Learning activities designed.

Innovative characteristics of the learning design are considered essential in the sense that the learning design promotes a student-centered learning environment that engages students in technology enhanced meaningful activities. The learning activities should not only be facilitated by the use of ICT in the teaching and learning process, they should also foster and promote new, alternative forms of teaching that are more compatible with modern pedagogical and teaching theories and ICT uses (Komis et al., 2013). The criteria (presented in Table 2) are assigned to performance level (Poor to Excellent) and numerically assessed in a range from 1 to 5. Additionally, there are two open questions (5.1 and 5.2), asking assessors to express their opinion about the worthwhile features of the learning design and suggest points that could be improved or that need change. Since this project serves summative assessment goals and the teacher wants to avoid making students feel uncomfortable by scoring their peer's work, the outcome counts towards a degree level qualification by measuring the corresponding number of points awarded to each criterion. Also, the teacher provides a descriptive assessment of the students' performance as assessors. 
Table 2

Assessment form criteria

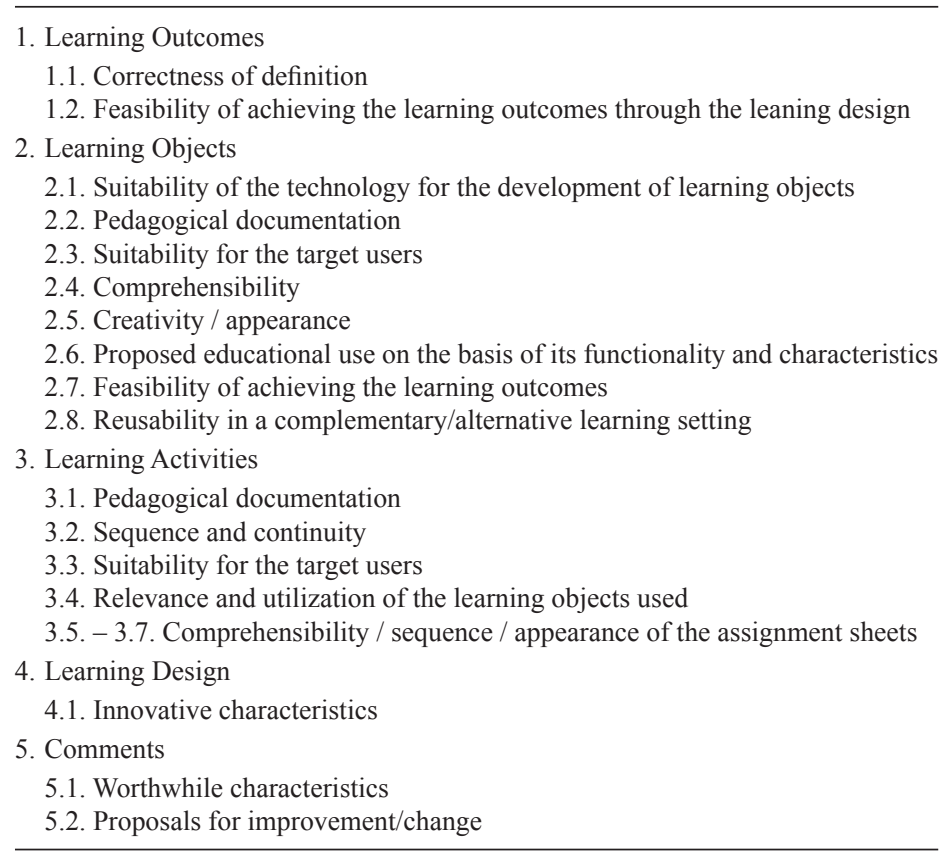

\subsection{Empirical Evaluation and Results}

In order to value the proposed framework of instruction and assessment, a study was performed in the context of one semester "Design and Implementation of Digital Educational Applications" course for two consecutive academic years (2018-2019 and 2019-2020). The sixteen (16) participants ( 8 men and 8 women) during the first year (Group A) and the eight (8) participants (7 men and 1 woman) during the second year (Group B) come from diverse scientific fields (e.g. Computer Science, Military, Cognitive Science). None of them had prior knowledge on the course topics.

The main research questions were:

1. Do the students consider that the interweaving of instruction and assessment supported them in learning design?

2. Did the assessors' comments and the role of the assessor help students in improving their design?

3. a) How did students act as assessors? b) Which is the inter-assessor agreement?

4. Do Google Forms serve adequately the peer assessment activity?

The research tools were a) the Google Forms (Table 2, assessment criteria) submitted as feedback to peer assessment, b) a questionnaire filled by the students asking them, among other things, to express their opinion about the lab activities and the learning de- 
sign peer assessment project they worked on as well as about the feedback they received, and c) the reports they provided as reflection to the feedback they received in the context of the peer assessment.

From Group A, twelve persons worked in pairs and the rest on their own. In total 10 learning designs were submitted covering diverse topics. Regarding Group B, all students worked on their own, submitting eight different learning designs.

For the peer assessment phase, the teacher appointed to each learning design the corresponding assessor. In case of pairs, each student had to submit the assessment form separately and afterward to collaborate and jointly submit one.

Results: 1. Do the students consider that the interweaving of instruction and assessment supported them in learning design?

The students believe that the whole framework helped them to identify educational features in educational applications attributed to specific learning theories, to design their own applications and to develop skills in the design of learning activities and in the learning design in general (Fig. 2). Indicative comments include "the activities were very interesting. I used a lot of tools that are very useful for teaching and learning in various contexts", "the activities helped me to understand the theory and to practice", "the activities helped a lot in the final project. The engagement in different activities every week, gave me the chance to devote effort and time, to learn educational tools, to discuss learning design issues and make clear how to work for the project", "It would be interesting and helpful to collaborate in some of the activities". The students stood high in their account the time devoted to lab activities as well as the content of the activities and stressed that it could be of great worth to have more time to deepen further and gain insight into the features of effective and constructive learning activities. They consider that the combination of theory and lab activities enabled them to understand theoretical issues and to practice in leaning design issues.

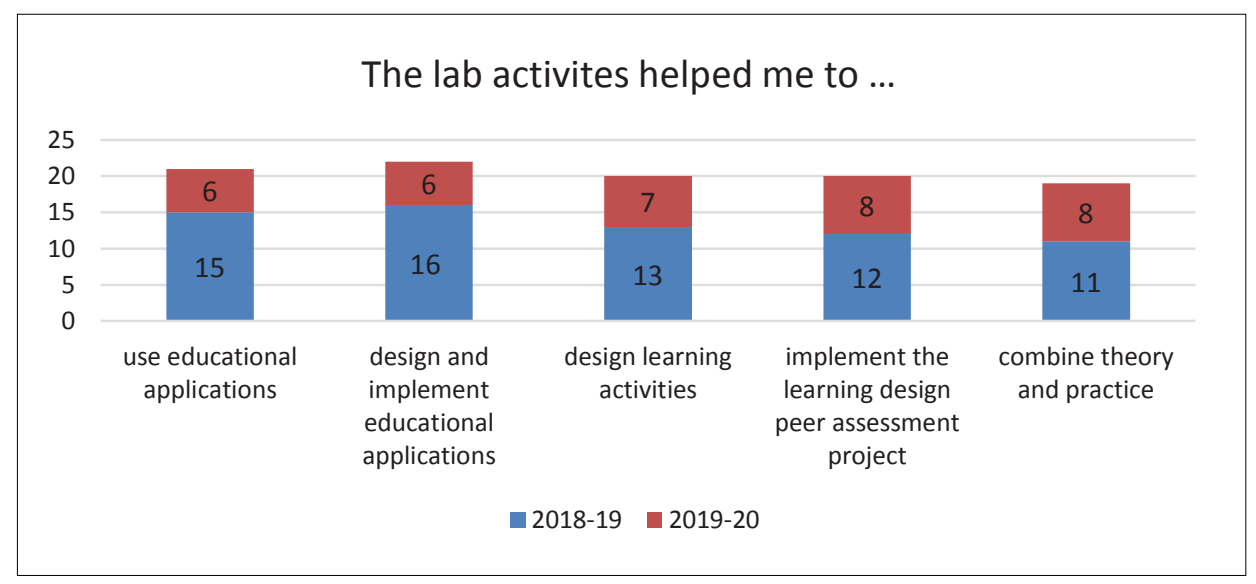

Fig. 2. Students' opinion on the lab activities they worked on. 
In line with this view, students appreciate as very helpful (16 students) and helpful (6 students) the feedback provided for each lab activity; the comments were characterized as very targeted and constructive ("The form of assessment was innovative, outside the box. It was very constructive and helped me to understand concepts that seemed to be difficult."). They also appreciated the face-to-face discussions, the time and effort devoted to personal feedback. They expressed their desire to allot time for additional lab activities in order to become acquainted with contemporary tools for learning objects development. Moreover, on their reflection report, they valued their engagement in the peer assessment project and they consider that the presentation of the learning designs and the discussion on their strengths and weaknesses helped them to reconsider their own learning design and understand essential characteristics. In line with Adachi and her colleagues (2018), students stated that acting as assessors, they enhanced their understanding of success criteria, although the assessment form was available from the beginning of the project. They mentioned that only during assessor's phase, they paid attention to the assessment criteria and comprehended their meaning and importance ("the use of rubric made clear the points that we should focus and work harder during the design").

Results: 2. Did the assessors' comments and the role of the assessor help students in improving their design?

All students noted that the role of the assessor helped them in reflecting on their own learning design, thinking of improvements and consider alternative ways of structuring learning activities and utilizing Web2.0 tools to develop learning objects. Indicative comments include "I understood better the specifications of the learning design and the drawbacks of my design", "I saw interesting ideas in how to organize an assignment sheet", "Very good ways of utilizing Web 2.0 tools", "Some learning objects and activities were very creative". On their reflection report, all of the students appreciated that the assessors noticed the positive features of their design and tried to delve deeply and propose major and targeted changes. As a next step, they made the best of the received comments and the discussion that took place in the class, and proposed changes to improve and reformulate their own learning design. The majority focused on adjustments and revisions for more constructive learning activities and the improvement of the assignment sheets in order to reflect the context and aim of the learning activities and take into account the characteristics of the target group.

\section{Results: $3 a$. How did students act as assessors?}

The students acted with responsibility and integrity attempting to gain insight to their assessee's learning design and understand the leaning objects developed and the learning activities designed.

Results: $3 b$. Which is the inter-assessor agreement?

Fig. 3a represents the difference between peer's grade and teacher's grade for each one of the 16 students of Group A (10 learning designs, the first four by one student while the rest in pairs), while Fig. 3b represents the difference between peer's grade and teacher's 


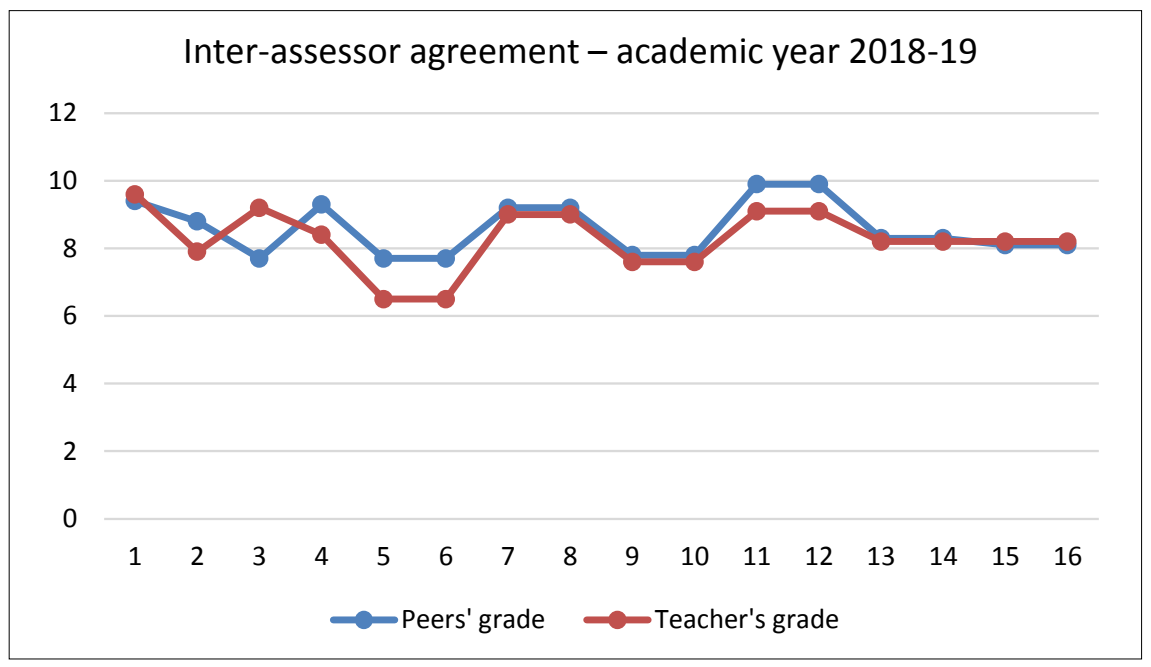

(a)

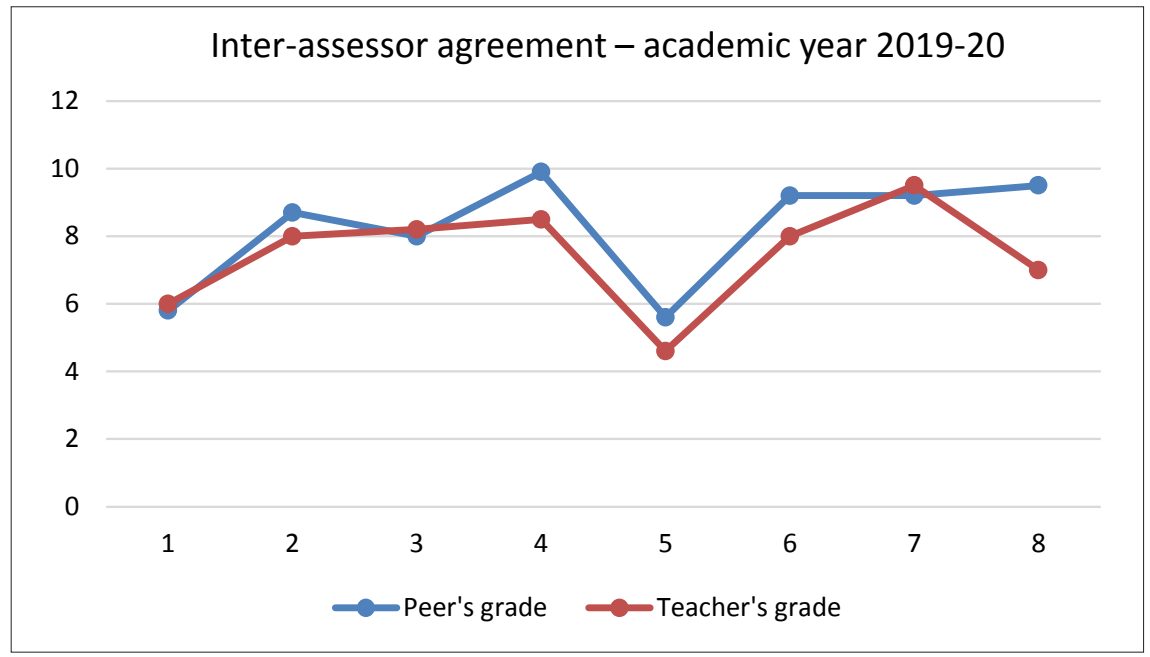

(b)

Fig.3. Inter-assessor agreement, (a) - academic year 2018-2019, (b) - academic year 2019-2020.

grade for each one of the 8 students of Group B. The differences are ascribed mainly to the assessment criterion of the correctness of the formulation of the learning outcomes and the pedagogical documentation of learning objects and learning activities. As the students didn't have at their disposal the assessee's report and their assessment/feedback was based on the presentation given, it seems reasonable to overlook such issues.

Results: 4. Do Google Forms serve adequately the peer assessment activity?

The teacher's view of Google Forms as a practical and flexible tool to serve assessment purposes is in line with other researchers' views (Douell, 2020; Nguyen et al., 2018). 
Administering Google Forms requires only a few minutes. The students easily navigated and responded to each question. The teacher collected all the assessment forms in a spreadsheet form, filtered/sorted them according to the assessee's name and emailed to each student the feedback submitted.

\section{Conclusions}

The findings of the study show that the interweaving of instruction and assessment and the students' active involvement in lab activities and a peer assessment project form a learning environment that may contribute to the understanding of the main learning design issues and to the cultivation of skills in both the development of educational applications as well as in the design of technology enhanced learning activities. Peer assessment forms a core part of formative assessment practices. Reviewing peers' work helps students become better reviewers of their own work and to revise and improve their own work (Rollinson, 2005; Henderson et al., 2019). The students' comments and reflection report revealed that it is useful to perform each of the roles (i.e. assessor and assessee). Assessing makes students qualified to draw comparisons with peers' work and increased familiarity with evaluative criteria thus improving academic performance (Double et al., 2020). The assessment form in the form of rubric seems to made students to be more accurate; as stated by Panadero and his colleagues (2013) the students are less likely to overscore their peers.

The fundamental principles of the proposed framework may be deployed in the context of any course, providing a basis for structuring a course curriculum around student-centered activities, sustainable assessment and feedback practices. The importance of active learning for student achievement has been well-established in higher education (Noben et al., 2020). The goal of instruction is not only to present new knowledge but more importantly to give learners guidance about how to apply and manipulate knowledge towards achievement of learning goals. The presented framework may guide instructors to reconsider their teaching practices in the direction of adopting and applying approaches that trigger student involvement and student achievement. The redesign of learning material and its enrichment with activities that address learning outcomes at different levels, the provision of focused, personal-oriented and interactive feedback and the integration of well-structured peer activities may help students. Greater understanding of formative assessment forms and peer assessment as a powerful pedagogical practice to ensure students develop competencies should be a key goal in teachers' development. The teachers may gradually redesign their course, by including activities that drive to a more constructive and interactive learning situations. For example, as a first step the teacher may enrich the teaching process with activities that (i) ask students to discuss main topics using the discussion feature of a learning management system and s/he follows by giving hints and feedback, (ii) ask students to collaborate in pairs or small groups and carry out an assignment and present their work using the learning management systems and also to comment on the work of another group. 
Active learning and formative assessment is much easier to implement within smaller groups of students (Santos et al., 2019). The time and effort needed to design suitable learning and peer assessment activities as well as to provide timely feedback for each student, is considerable. The class size is a key factor in the provision of timely and constructive feedback and in organizing and managing peer assessment projects (Gilbert et al., 2020). The need for technology use and further human resources should be considered and examined in order to support larger groups and cultivate an attitude of assessment for learning.

The proposed framework may be enriched with lab activities that prescribe collaboration in various contexts and phases. A couple of students expressed their willingness to work in pairs so that exchange ideas and help each other. It seems that additional time has to be devoted to such activities; discussion, dedicated examples and commenting on learning designs may support and further promote students' work. Our findings are consistent with current theories of formative assessment and instructional best practices that provide strong empirical support for the continued use of peer assessment in the classroom and other educational contexts (Double et al., 2020). A challenge towards the direction of interweaving peer assessment with the proposed framework, would be the reformulation of the lab activities on the basis of a multi-cycle peer assessment as empirical research has indicated that such an approach can improve students' capabilities in developing pedagogical worthy learning objects and in assessing their peers' work (Gogoulou and Grigoriadou, 2019).

\section{References}

Adachi, C., Tai, J.H.M., Dawson, P. (2018). Academics' perceptions of the benefits and challenges of self and peer assessment in higher education. Assessment \& Evaluation in Higher Education, 43(2), 294-306.

Armellini, A., Aiyegbayo, O. (2010). Learning design and assessment with e-tivities. British Journal of Educational Technology, 41(6), 922-935.

Barnard, A., Croft, W., Irons, R., Cuffe, N., Bandara, W., Rowntree, P. (2011). Peer partnership to enhance scholarship of teaching: A case study. Higher Education Research and Development, 30, 435-448.

Bates, A.W. (2019). Teaching in a Digital Age. Guidelines for Designing Teaching and Learning. https://opentextbc.ca/teachinginadigitalage/

Berry, R. (2008). Assessment for learning. Hong Kong University Press.

Black, P., Harrison, C. Lee, C. Marshall, B., Wiliam, D. (2003). Assessment for Learning: putting it into practice. Open University Press: Maidenhead.

Carless, D. (2015). Excellence in University Assessment: Learning from Award-Winning Practice. Routledge.

Celik D., Magoulas G.D. (2016). A Review, Timeline, and Categorization of Learning Design Tools. In: Chiu D., Marenzi I., Nanni U., Spaniol M., Temperini M. (Eds), Advances in Web-Based Learning - ICWL 2016. ICWL 2016. Lecture Notes in Computer Science, vol 10013. Springer, Cham. https://doi.org/10.1007/978-3-319-47440-3_1

Conole, G. (2010). Learning design - Making practice explicit. In: ConnectEd 2010, 2nd International Conference on Design Education, 28 June - 1 July 2010, Sydney, Australia.

Conole, G. (2013). Designing for learning in an open world. New York, NY: Springer.

Davies, P. (2006). Peer assessment: judging the quality of students' work by comments rather than marks. Innovations in Education and Teaching International, 43(1), 69-82.

Djenno, M., Insua, G.M., Pho, A. (2015). From paper to pixels: using Google Forms for collaboration and assessment. Library Hi Tech News, 32(4), 9-13. 
Dosch, M., Zidon, M. (2014). The Course Fit Us: Differentiated instruction in the college classroom. International Journal of Teaching and Learning in Higher Education, 26(3), 343-357.

Double, K.S., McGrane, J.A., Hopfenbeck, T.N. (2020). The Impact of Peer Assessment on Academic Performance: A Meta-analysis of Control Group Studies. Educational Psychology Review, 32, 481-509. https://doi.org/10.1007/s10648-019-09510-3

Douell, M. (2020). Integrating Google Forms as a Means of Formative Assessment in the Elementary Math Classroom. Honors Theses. 1467. https://egrove.olemiss.edu/hon_thesis/1467

Ernst, H.R., Ernst, T.L. (2005). The promise and pitfalls of differentiated instruction for undergraduate political science courses: Student and instructor impressions of an unconventional teaching strategy. Journal of Political Science Education, 1, 39-59.

Gibbs, G, Simpson, C. (2004). Conditions under which assessment supports students' learning. Learning and Teaching in Higher Education, 1, 3-31.

Gibbs, G. (2006). How assessment frames student learning. In: C. Bryan, \& K. Klegg (Eds.), Innovative Assessment in Higher Education. Abingdon: Routledge.

Gielen, M., Wever, B.D. (2012). Peer Assessment in a Wiki: Product Improvement, Students' Learning and Perception Regarding Peer Feedback. Procedia : Social \& Behavioral Sciences, 69, 585-594.

Gilbert, A. (2016). The lecture: Have reports of its death been greatly exaggerated? In: Davis, M., Goody, A. (Eds.), Research and Development in Higher Education: The Shape of Higher Education, 39, 85-95. Fremantle, Australia, 4-7 July 2016.

Gilbert, A., Tait-McCutcheon, S., Knewstubb, B. (2020). Innovative teaching in higher education: Teachers' perceptions of support and constraint. Innovations in Education and Teaching International, 1-12.

Gipps, C. (2011). Beyond Testing: Towards a Theory of Educational Assessment. Routledge Education Classic Edition, London.

Gogoulou A., Grigoriadou M. (2019) Engaging Postgraduate Students in a Wiki-Based Multi-cycle Peer Assessment Activity. In: Tsitouridou M., A. Diniz J., Mikropoulos T. (Eds.), Technology and Innovation in Learning, Teaching and Education. TECH-EDU 2018. Communications in Computer and Information Science, vol 993. Springer, Cham. https ://doi.org/10.1007/978-3-030-20954-4_44

Haddad, R.J., Youakim, K. (2014). Google Forms: A real-time formative assessment approach for adaptive learning. In: Proceedings of the 2014 American Society for Engineering Education, ASEE Annual Conference and Exposition. Indianapolis, Indiana. https : //peer . asee.org/20540

Hawe, E., Dixon H. (2017). Assessment for learning: A catalyst for student self-regulation. Assessment \& Evaluation in Higher Education, 42(8), 1181-1192. DOI: 10.1080/02602938.2016.1236360

Henderson, M., Ryan, T., Phillips M. (2019). The challenges of feedback in higher education. Assessment \& Evaluation in Higher Education, 44(8), 1237-1252. DOI: 10.1080/02602938.2019.1599815

Hernández-Leo, D., Asensio-Pérez, J.I., Derntl, M., Pozzi, F., Chacón-Pérez, J., Prieto, L.P., Persico, D. (2018). An integrated environment for learning design. Frontiers in ICT, 5(9). DOI: 10.3389/fict.2018.00009

Jääskelä, P., Häkkinen, P., Rasku-Puttonen, H. (2017). Teacher Beliefs Regarding Learning, Pedagogy, and the Use of Technology in Higher Education. Journal of Research on Technology in Education, 49(3-4), 198-211. DOI: 10.1080/15391523.2017.1343691

Kazanidis, I., Pellas, N., Fotaris, P., Tsinakos, A. (2018). Facebook and Moodle integration into instructional media design courses: A comparative analysis of students' learning experiences using the Community of Inquiry (CoI) model. International Journal of Human-Computer Interaction (Taylor \& Francis), 38(10), 932-942

Komis, V., Tzavara, A., Karsenti, T., Collin, S., Simard. S. (2013). Educational scenarios with ICT: An operational design and implementation framework. In: Society for Information Technology \& Teacher Education International Conference. Association for the Advancement of Computing in Education (AACE), 3244-3251.

Koper, R. (2006). Current research in Learning Design. Educational Technology \& Society, 9(1), 13-22.

Laurillard, D. (2008). Technology enhanced learning as a tool for pedagogical innovation. Journal of Philosophy of Education, 42(3-4), 521-533.

Ng, E., Lai, Y.C. (2012). An Exploratory Study on Using Wiki to Foster Student Teachers' Learner-centered Learning and Self and Peer Assessment. Journal of Information Technology Education: Innovations in Practice, 11, 71-84.

Nguyen, H., Stehr, E.M., Eisenreich, H., An, T. (2018). Using Google Forms to Inform Teaching Practices. In: Proceedings of the Interdisciplinary STEM Teaching and Learning Conference. Vol. 2, Article 10. https://digitalcommons.georgiasouthern.edu/stem_proceedings/vol2/iss1/10 
Noben, I., Deinum, J.F., Hofman, W.A. (2020). Quality of teaching in higher education: reviewing teaching behaviour through classroom observations. International Journal for Academic Development, 1-16. DOI: 10.1080/1360144X.2020.1830776

Panadero, E., Brown, G.T.L. (2017). Teachers' reasons for using peer assessment: positive experience predicts use. Eur J Psychol Educ, 32, 133-156. https://doi .org/10.1007/s10212-015-0282-5

Panadero, E., Romero, M., Strijbos, J.W. (2013). The impact of a rubric and friendship on peer assessment: Effects on construct validity, performance, and perceptions of fairness and comfort. Studies in Educational Evaluation, 39(4), 195-203.

Pellegrino, J., Chudowsky, N., Glaser, R. (2001). Knowing what students know: The science and design of educational assessment. Washington DC: National Academy Press.

Popescu E., Petrosanu LM. (2017). Integrating a Peer Evaluation Module in a Social Learning Platform. In: Popescu E. et al. (Eds.), Innovations in Smart Learning. Lecture Notes in Educational Technology. Springer, Singapore, 141-150.

Postareff, L. Lindblom-Ylänne, S., Nevgi, A. (2007). The effect of pedagogical training on teaching in higher education. Teaching and Teacher Education, 23, 557-571.

Rollinson, P. (2005). Using Peer Feedback in the ESL Writing Class. ELT Journal, 59, $23-30$.

Santos, J., Figueiredo, A. S., Vieira, M. (2019). Innovative pedagogical practices in higher education: an integrative. Nurse Education Today, 72, 12-17.

Sadler, D.R. (1989). Formative assessment and the design of instructional systems. Instructional Science, $18,119-144$.

Sambell, K. (2013). Involving students in the scholarship of assessment: student voices on the feedback 'agenda for change'. In: Merry, S., Price, Carless M. D., Taras, M. (Eds.), Reconceptualising feedback in higher education: Developing dialogue with students. London: Routledge, 80-91.

Sambell, K. (2016). Assessment and feedback in higher education: considerable room for improvement? Student Engagement in Higher Education, 1(1).

Shirani Bidabadi N., Nasr Isfahani A, Rouhollahi A, Khalili R. (2016). Effective Teaching Methods in Higher Education: Requirements and Barriers. Journal of Advances in Medical Education \& Professionalism, 4(4), 170-178.

Sluijsmans, D., Dochy, F., Moerkerke, G. (1999). Creating a learning environment by using self-, peer- and co-assessment. Learning Environments Research, 1, 293-319.

Strijbos, J., Sluijsmans, D. (2010). Unravelling peer assessment: Methodological, functional, and conceptual developments. Learning and Instruction, 20 (4), 265-269.

Sung, Y-T., Chang, K-E., Chiou S-K., Hou H-T. (2005). The design and application of a web-based self- and peer-assessment system. Computers \& Education, 45, 187-202.

Topping, K. (1998). Peer assessment between students in colleges and universities. Review of Educational Research, 68(3), 249-276.

Topping, K.J. (2010). Methodological quandaries in studying process and outcomes in peer assessment: Commentary. Learning and Instruction, 20(4), 339-343.

Topping, K. (2017). Peer Assessment: Learning by Judging and Discussing the Work of Other Learners. Interdisciplinary Education and Psychology, 1(1), 1-17. https://doi.org/10.31532/InterdiscipEducPsychol.1.1.007

Tsai, W.T., Li, W., Elston, J., Chen, Y. (2011). Collaborative learning using wiki web sites for computer science undergraduate education: A case study. IEEE Transactions on Education, 54(1), 114-124.

Wiley, D.A. (2000). Connecting learning objects to instructional design theory: A definition, a metaphor, and a taxonomy. In: Wiley, D.A. (Ed.), The Instructional Use of Learning Objects: Online Version. http://reusability.org/read/chapters/wiley.doc

William, D. (2011). What is assessment for learning? Studies in Educational Evaluation, 37, 3-14.

Zheng, L., Chen, N.S., Cui, P., Zhang, X. (2019). A Systematic Review of Technology-Supported Peer Assessment Research: An Activity Theory Approach. International Review of Research in Open and Distributed Learning, 20(5), 168-191. 
A. Gogoulou is Laboratory Teaching Staff in the Department of Informatics and Telecommunications, National and Kapodistrian University of Athens and research member of the Education and Language Technology Group. She participates in national and European Union projects. She has more than 50 publications in international journals, books, and proceedings of international conferences and more than 180 citations (Scopus) to her research work. Her research work focuses on the areas of computer science education, learning design, educational assessment, CSCL, adaptive learning environments, Web-based education, learner modeling. She has served as Program Committee member of several international and national conferences and is a reviewer to various journals.

M. Grigoriadou is now a Professor Emeritus in education and language technology and head of the Education and Language Technology Group of the Department of Informatics and Telecommunications, National and Kapodistrian University of Athens. She has more than 50 publications in international journals, 11 contributions in international book chapters, 150 in proceedings of international conferences, and more than 2000 citations to her research work. Her current research interests concern the areas of adaptive learning environments, Web-based education, ITS, educational software, natural language processing tools, and computer science education. Prof Grigoriadou is a Member of the ACM, AACE, IADIS, EDEN, Kaleidoscope, and LeMoRe. She has won seven awards and has participated in 30 national and European Union projects (15 as Project Manager and/or Senior Scientist). She has served as Program Committee member of several international conferences and co-organizer of international workshops. 